\title{
PREMATURE SYSTOLES ORIGINATING IN THE SINO-AURICULAR NODE
}

\author{
BY \\ R. LANGENDORF AND S. S. MINTZ \\ From the Cardiovascular Department, Michael Reese Hospital, Chicago, Illinois, U.S.A.* \\ Received July 15, 1946
}

Premature systoles arising in the sino-auricular node are characterized in the electrocardiogram by premature $\mathbf{P}$ waves that are identical in contour with other sinus $\mathbf{P}$ waves and by the absence of a prolongation of the returning cycle. Actually the returning cycle may be shorter than the normal cycle because of prolonged sino-auricular conduction of the premature beat (Wenckebach, 1908). According to Wenckebach and Winterberg (1927) slight changes in contour of the premature $\mathrm{P}$ wave do not rule out sinus origin of the premature impulse; these aberrant $P$ waves are ascribed to aberrant conduction in the auricles. Varying intra-auricular conduction has also been suggested (Scherf, 1945) to explain the altered contour of the sinus $\mathbf{P}$ wave that occurs in second degree auriculo-ventricular block, accompanied by shortening of the P-P intervals, in those P-P intervals containing a ventricular complex. It would appear that a contour of the premature $\mathbf{P}$ wave identical with that of the sinus $\mathbf{P}$ wave should be postulated for the diagnosis of sinus premature systoles in order to avoid confusion with auricular premature systoles. In exceptional cases, however, a diagnosis of sinus premature systoles seems justified in spite of a slightly different $\mathbf{P}$ wave contour when sinus arrhythmia is absent and when the returning cycle is equal to or shorter than the normal cycle. Because of their rarity, two more cases are being added in this paper to the few instances of sinus premature systoles reported (Wenckebach, 1908; Lewis, 1925; Clerc et al., 1938; Simon and Langendorf, 1944; and Geiger and Goerner, 1945).

Case 1. A man, aged 60, was admitted to the hospital because of neurological complaints. A cardiogram (Fig. 1) was taken to determine the nature of his irregular heart action. The patient had received no medication. Lead I shows an undisturbed regular sinus rhythm with a P-P interval of $0.98 \mathrm{sec}$; all the other leads show bigeminal rhythm with a P-P interval of $0.98 \mathrm{sec}$. alternating with a $P-P$ interval of $0.80 \mathrm{sec}$. There is a first degree A-V block (P-R equals $0.30 \mathrm{sec}$.) with variations in the $P-R(0.32$ and 0.34 sec.) in the leads with bigeminal rhythm. The $P$ waves show only minute differences in contour. The absence of a compensatory pause (the P-P interval in lead I equals the post-extrasystolic P-P intervals in the other leads) identifies the premature systoles as arising in the sino-auricular node. Comparison of lead I with the other leads permits exclusion of other possibilities to be considered in cases of persistent sinus bigeminy, such as non-conducted sinus premature systoles occurring after every second beat, $3: 2 \mathrm{~S}-\mathrm{A}$ block with the Wenckebach phenomenon, and alternans of the S-A conduction time.

Case 2. A woman, aged 80, having hypertensive cardiovascular disease, was admitted with a provisional diagnosis of a recent myocardial infarct. No drugs were administered. The cardiogram is shown in Fig. 2. The first seven beats in lead $I$ are regularly spaced and have a P-P interval of $0.64 \mathrm{sec}$. They are followed by a bigeminal rhythm throughout the rest of the record except for one occasion in lead $\mathrm{CF}_{2}$. A P-P interval of $0.64 \mathrm{sec}$. alternates with a P-P interval of $0.70 \mathrm{sec}$. However, the $P$ wave of the premature beat shows minute differences in contour and might suggest ectopic rather than sinus origin. The first seven beats in lead $I$ have to be considered as a run of premature systoles. This case illustrates the difficulty of distinguishing between sinus premature systoles and

* Aided by the Emil and Fanny Wedeles Fund for Cardiovascular Research. The department is supported in part by the Michael Reese Research Foundation. 


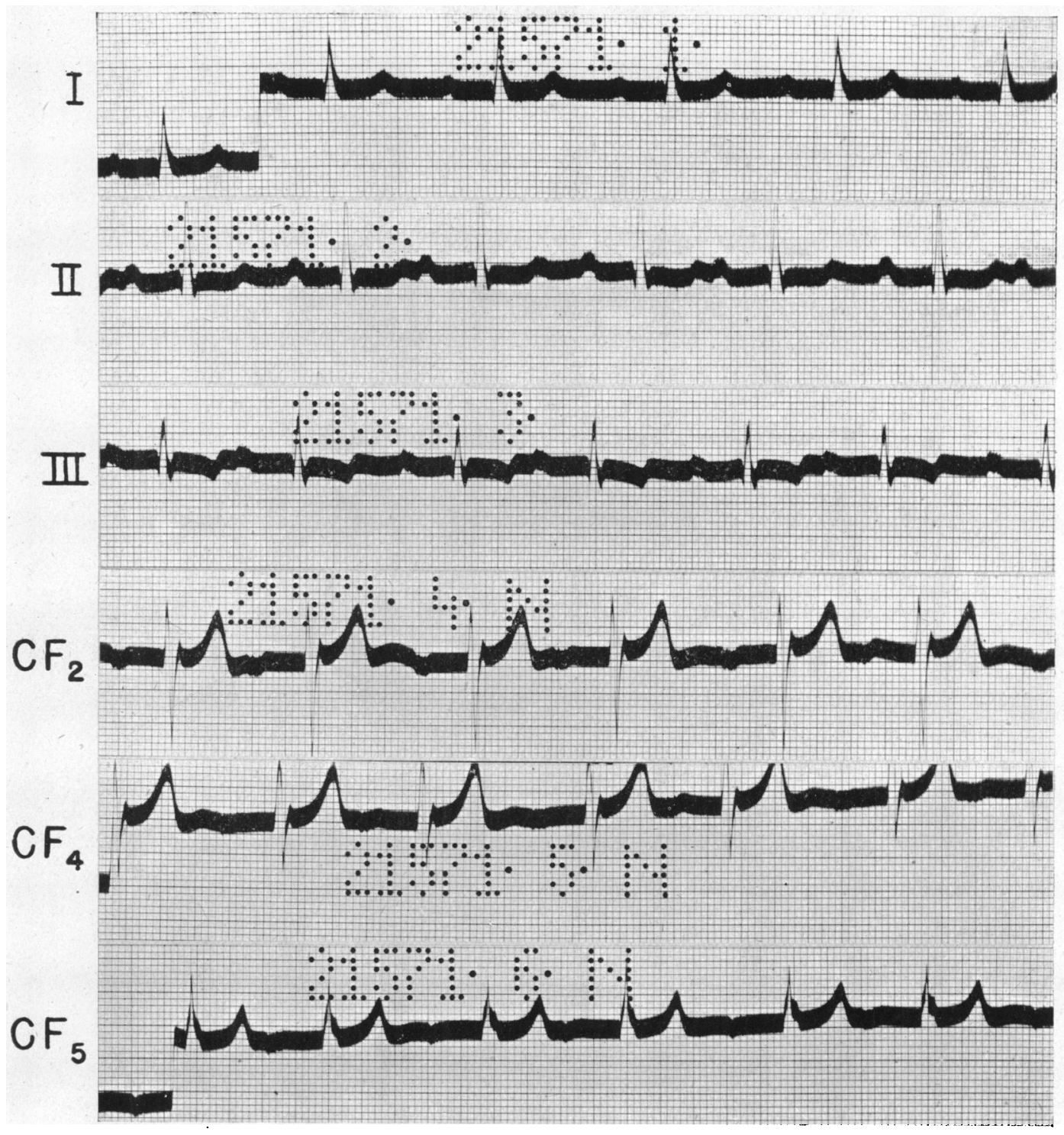

FIG. 1.-Premature systoles originating in the S-A node.

auricular premature systoles arising close to the sino-auricular node. The diagnosis is based in this case upon the close similarity of the premature $\mathbf{P}$ waves to the sinus $\mathbf{P}$ waves and is made despite the inability to compare the post-extrasystolic pauses with the sinus P-P interval.

\section{SUMmaRY}

The criteria of electrocardiographic diagnosis of premature systoles arising in the sinoauricular node are discussed and two new cases are described.

The diagnosis is made in spite of slight variations in the contour between the sinus $\mathbf{P}$ wave and the premature $P$ wave. In Case 1 the diagnosis is based on the finding of a returning cycle equal to the interval between two sinus $P$ waves in another lead without premature beats. In Case 2 the occurrence of bigeminal rhythm speaks against the diagnosis of simple sinus arrhythmia and favours the diagnosis of premature beats of sino-auricular origin because of the close similarity of the premature $P$ waves to the sinus $P$ waves; however, the diagnosis of auriculàr premature systoles arising from a focus close to the sinus node cannot be ruled out.

We are indebted to Dr. L. N. Katz for his criticism and aid in preparing this paper. 


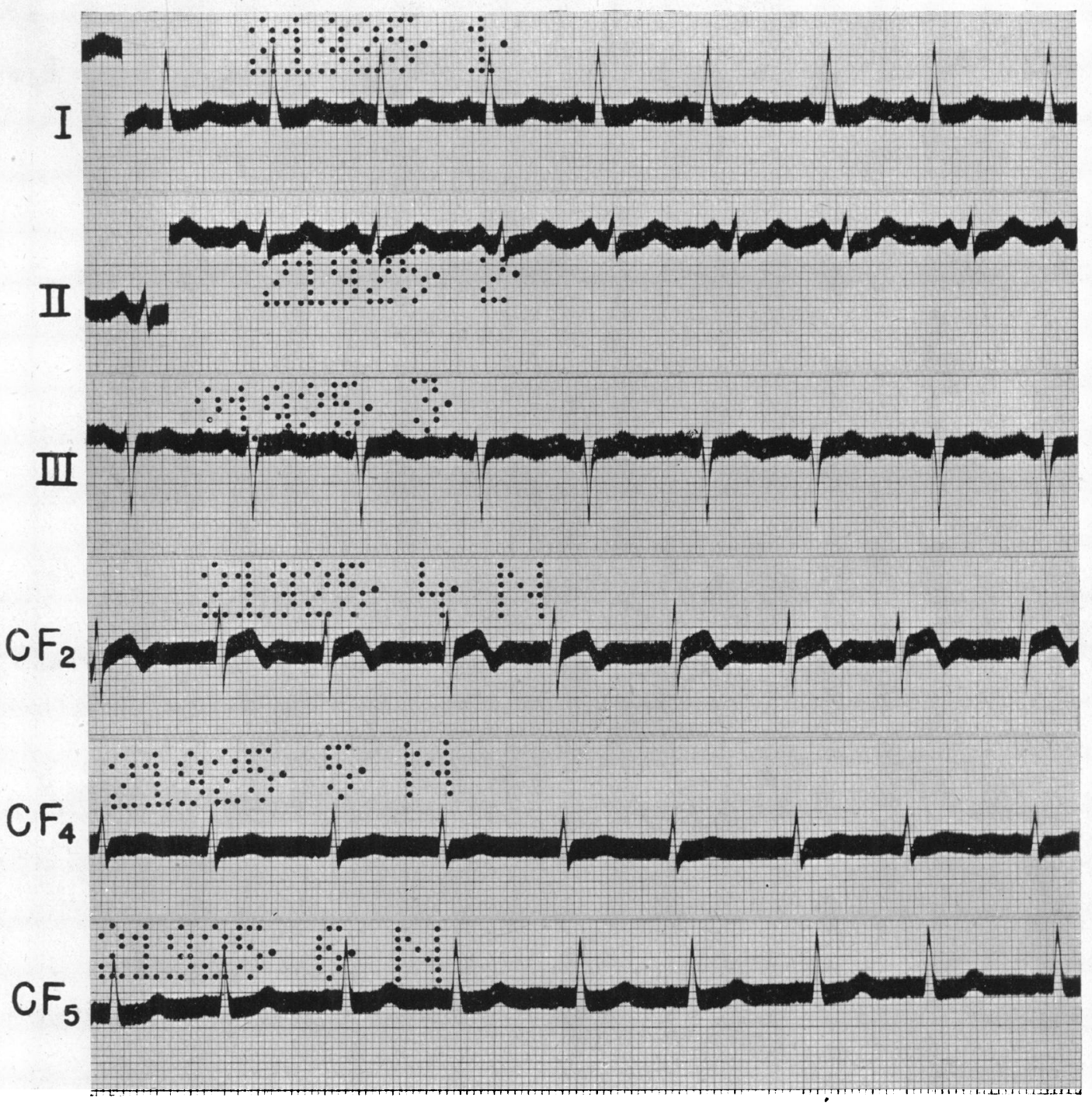

FIG. 2.-Premature systoles originating in the S-A node.

\section{REFERENCES}

Clerc, A., Levy, R., and Calo, A. (1938). Arch. Mal. Coeur, 31, 1175.

Geiger, A. J., and Goerner, J. R. (1945). Amer. Heart J., 30, 284.

Lewis, T. (1925). "The Mechanism and Graphic Registration of the Heart Beat," 3rd ed., Shaw and Sons, London.

Scherf, D. (1945). Amer. Heart J., 29, 213.

Simon, A. J., and Langendorf, R. (1944). Ibid., 27, 345.

Wenckebach, K. F. (1908). Arch. Anat. Phys. (Phys. Abt.) 1, 1907, and III. Tëil Suppl., 53, 1908.

- and Winterberg, H. (1927). " Die unregelmässige Herztätigkeit." Wilhelm Engelmann, Leipzig. 